\title{
Campo de migrações: Fabiano, Manuel, Ranulfo e os anônimos do sertão*
}

* Este artigo é a transcrição de uma conferência proferida na abertura da International Conference "Cultures in Transit", ocorrida na University of Ottawa, de 4 a' 6 de maio de 2006. Para o leitor brasileiro, há aqui passagens sobre o Cinema Novo que são resumos de textos já publicados, mas não era o caso de suprimi-las, dado o risco de perda de unidade. Quanto às observações sobre o contemporâneo, o que digo sobre Baile Perfumado e o "encontro inesperado" está relacionado com a minha entrevista à revista Praga n.9 (junho de 2000).

ISMAIL XAVIER Escola de Comunicações e Artes - ECA/USP 


\section{Resumo}

Esse artigo compara filmes brasileiros recentes - "Baile perfumado" (1996) e "Cinema, aspirinas e urubus" (2005) - com clássicos de Cinema Novo, como "Vidas secas", "Os fuzis" e "Deus e o diabo na terra do sol". Seu objeto é o deslocamento ocorrido nos anos 1990 na representação da experiência migratória do sertão. A análise destaca a maneira como os filmes concebem seus personagens principais e dão sentido às suas experiências, 'tanto em conexão com a representação de tipos sociais para os quais a migração é uma necessidade social (Cinema Novo), quanto a representação de indivíduơ que enfrentạm encontros inesperados e vivem a migração como uma experiência singular, revestida de um caráter transnacional (produções das últimas décadas).

\section{Palavras-chave}

cinema brasileiro, Cinema Novo, cinema contemporâneo, sertão

\section{Abstract}

This article compares recent Brazilian films - "Baile perfumado" (1996) and "Cinema, aspirinas e urubus" (2005) - with classic Cinema Novo films, like "Vidas secas", "Os fuzis" and "Deus e o diabo na terra do sol". It focuses on the displacement that took place in the representation of the experience of migration in the sertão from the 1990 's on. The analysis concentrates in the way the films conceive their main characters and give meaning to their experience, either in connection with the representation of social types living migration as a social need (Cinema Novo) or in connection with the representation of particular individuals who face unexpected encounters and live migration as a singular experience of a transnational character (films from the last decades).

\section{Key words}

brazilian cinema, Cinema Novo, contemporary cinema, wilderness 


\section{Introdução}

oloco aqui três termos em relação: um lugar (o sertão), uma experiência (a migração) e um meio de representação (o cinema). E meu percurso, desta feita, tem como ponto de chegada o filme Cinema, aspirinas e urubus (2005), de Marcelo Gomes, que o inspirou.

No Brasil, o sertão é um lugar mítico dentro do processo de construção de identidade nacional, com forte presença nas formulações do século XIX e da primeira metade do século XX: a vasta região do semi-árido do interior brasileiro (centro-oeste e nordeste) é a região emblemática da seca e da miséria ligada à concentração da propriedade da terra, herança dos tempos coloniais. Tomando as célebres referências literárias, há o sertão do buriti e "dos gerais" (norte de Minas e Goiás, o mundo de Guimarães Rosa), e há o sertão de Canudos e das vidas secas, o mundo de Euclides da Cunha e Graciliano.Ramos.

Dentro de uma certa ordem de idéias, esta distinção não ganha maior relevo, e há uma tradição de crítica literária que pensa essas duas regiões como elos de uma continuidade que permite fazer a ponte entre esses escritores. Eles são diferentes, mas partem do mesmo eixo de questões referidas ao complexo cultural, social, econômico da "civilização do couro" (assim chamada porque cresceu com a criação de gado, sua principal atividade por muito tempo). Deste complexo cultural, a literatura e o cinema deram ênfase à constituição de um tipo, o vaqueiro, com seu modo de ser que se contrapõe à vida e à cultura em outras regiões. Vale então, na ficção, a idéia do sertão como unidade, e prevalece a análise das formas 
como essa identidade foi sendo concebida a partir do regionalismo literário do século XIX, num processo onde se ressaltou, de modo crescente, uma 'lógica interna", ou seja, formas próprias de cultura e de distribuição do poder, traços a partir do quais se passou a explorar o significado dessa unidade para além de sua condição regional. $O$ sertão se torna um símbolo, ou uma síntese, de totalidades mais amplas, saltando do particular para o universal, como em Grande sertão: veredas, onde o sertão é o mundo.

O cinema herda esta tradição e, a partir do Cinema Novo, há um variado percurso que tem como referência maior a trilogia dos anos 1963-1964:

(1) Vidas Secas (1963), de Nelson Pereira dos Santos, um filme que adapta o romance de Graciliano Ramos e busca uma forma de olhar o sertão e a família de sertanejos em sua rotina (seu trabalho, sua luta contra natureza, suas migrações), explorando o espaço, a luz e a duração das imagens;

(2) Deus e o diabo na terra do sol (1963), de Glauber Rocha, que dialoga com Euclides da Cunha e José Lins do Rego, para evocar a Guerra de Canudos, em que os beatos seguidores de Antônio Conselheiro foram massacrados pelo exército brasileiro, em 1897, e o mundo dos cangaceiros seguidores de Lampião; Glauber escolheu uma representação alegórica com um viés totalizante, e a jornada dos protagonistas se organiza como a peregrinação à procura de um Bem, a Justiça. Trata-se de uma alegoria do Brasil que impressionou a todos, pela força do estilo, com uma invenção formal que permitiu aproximações com o paradigma “Guimarães Rosa" no confronto entre mito e história.

(3) Os fuzis (1963), de Ruy Guerra, filme que focaliza o confronto entre uma massa de retirantes, sertanejos pobres migrando para fugir da seca, e um grupo de soldados da polícia militar enviada ao sertão para proteger propriedades; aqui, o estilo é realista e se concentrà no estranhamento, distância radical, entre o habitante do sertão e o olhar do citadino (que se identifica com o do cinema). 
Desde então, a imagem do sertão tem sempre retornado no cinema, compondo já uma iconografia feita do diálogo entre muitos filmes. Fenômenos como o da peregrinação messiânica em busca da salvação, ou ciclos de violência endêmica gerados pelas ações de bandidos sociais (Hobsbawn, 1975) como o cangaceiro, são temas constantes, e o sertão permanece a referência maior quando se trata de escolher um imaginário pré-urbano, pouco afetado pela modernização do país até, pelo menos, os anos Juscelino Kubitscheck (1956-1960). Vê-se aí uma espécie de reservatório de identidade que, pela constância é suposta homogeneidade, é tomado como um dos emblemas maiores da brasilidade por nacionalistas obcecados pela idéia de raízes e pela preservação da cultura regional popular.

Cinema de autor dos anos 60 tomou a região como espaço recorrente de debate, em parte em função dessa simbologia em torno da identidade nacional, mas concentrou as suas forças na representação do sertão como um problema político, preocupado com as heranças coloniais, a pobreza e a religião, a violência do poder e a ausência de justiça. Nesta perspectiva, fez do camponês pobre que se afasta da fome indo para o litoral ou para o sudeste, um personagem típico, como se vê na trilogia. É na condição de vaqueiro (quando inserido num ciclo de trabalho sob comando de um "coronel"), ou de retirante, que o sertanejo aparece, em situaçổes nas quais o que interessa representar é seu modo de vida como exemplo de carência extrema, e sua mentalidade como exemplo de devoção religiosa nos termos de um catolicismo popular que pode se canalizar, em casos extremos, para a experiência messiânica. Quanto à sua relação com a violência, esta pode estar inserida na rotina, dentro do quadro das disputas de poder entre os coronéis (o sertanejo compõe o exército de jagunços), ou pode fazer parte de seu exílio diante da ordem do trabalho, quando escolhe entrar para o cangaço (muitas vezes porque não tem outra saída) e ligar seu destino ao do bando a que adere. De distintas formas, compõe-se um campo das migrações, que pode ser do simples retirante em fuga, do beato à busca da salvação da alma ou do cangaceiro em seus movimentos táticos na condução de sua guerra. Nesse campo, o cinema encontrou o material dramático para compor as suas estórias, enfrentando o desafio de 
inventar um olhar para este espaço, pois ele é uma mescla de identidade mítica e de alteridade efetiva. Este senso de alteridade é mais radical nos filmes dos anos 60 , onde os traços de modernidade se fazem ausentes do sertão, o que torna a própria presença do aparato do cinema um dado preliminar dessa migração exploratória. Antes de tudo, é o cineasta que se desloca para, filmando em locação, ter o embate com este mundo.

Posto este problema em sua dupla direção ou seja, a da relação do sertanejo com o mundo da técnica moderna, e a da relação do próprio cinema com o sertão - vou apontar aqui a mudança de enfoque e de sensibilidade que se constata entre os anos 1960 e o ano 2000 , mudança que inclui o modo como o cineasta olha para tal mundo e a sua própria auto-imagem ao conceber seu papel social. Trata-se, enfim, de uma comparação que se apóia no fato de que, tanto a trilogia de 1963, quanto os filmes recentes que vou comentar narram experiências que tiveram lugar no mesmo período histórico, anos 1930-40, mas que são representadas de modo bem diferente. Destacarei um deslocamento revelador: partimos de uma imagem do sertão como unidade isolada, espaço coeso e homogêneo na conformação de habitantes que revelam um tipo humano característico, à margem de qualquer modernidade, e chegamos a uma imagem do sertão como mundo permeável, lugar de encontros inesperados entre o sertanejo e figuras que vem de outros lugares e outras culturas, indicando a inserção desse espaço geográfico no circuito de trocas que incluem bens de consumo modernos, o comerciante árabe, o funcionário alemão e o próprio mundo do cinema.

\section{Migrações no Cinema Novo}

O Cinema Novo apresentou, nos anos 1960-70; um número considerável de filmes com nítido empenho em formular um diagnóstico geral da situação brasileira. Procurou formas de representação centradas na idéia do nacional, que tornassem as personagens encarnações de forças sociais em conflito (eixo políticoeconômico) ou encarnações de um "perfil brasileiro" de comportamento e valores (eixo da identidade). A história do país foi 


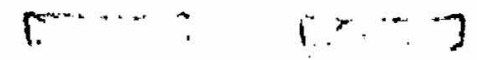

Campo de migraçōes: Fabiano, Manuel, Ranulfo ...

observada como um o terreno para alegorias, representações do passado voltadas para a construção de um diagnóstico do país referido ao presente e ao futuro, como em Deus e o diabo na terra do sol, filme que recapitula episódios decisivos da história do. sertão para evidenciar uma tradição de violência aí presente. A jornada do casal de camponeses - Manuel e Rosa - é vivida como uma sucessão de etapas de uma procura, e temos uma representação que transfigura a história (tempo) nos termos de uma aventura feita de deslocamentos espaciais. Neste caso, associam-se valores a lugares, e uma certa teleologia da história (tempo) torna-se visível, porque o estilo do filme a expressa no seu desenvolvimento, no estilo de suas imagens e nas suas metáforas. Aidéia é, de início, denunciar a exploração do trabalho e expor as condições materiais de vida, ou seja, a mesma faina de todos os dias, também presente na vida de Fabiano, o vaqueiro de Vidas Secas. Em termos de estilo, tanto o realismo de Nelson Pereira quanto a alegoria de Glauber Rocha procuraram a representação da experiência limite, de famílias isoladas no sertão, distantes da cidade; a filmagem em locação buscava produzir um sentimento de partilha, proximidade, no espectador. Ambos, neste sentido, criticaram o lado monumental do filme de cangaço de aventuras, como em $O$ Cangaceiro, de Lima Barreto, feito em 1953, filme em que a hipérbole nacionalista se fez espetáculo e a experiência do cangaço se tornou um "filme de gênero", como o western. Daí a procura de um novo estilo de captar a luz, de definir o lugar da natureza em função de sua relevância para a vida prática, de compor o rosto, o gesto e a palavra segundo o imperativo da autenticidade. Inventar um olhar que atravessasse a distância - Vidas Secas - ou a denunciasse, como o fez Ruy Guerra, em Os Fuzis, que trabalha o contraste irremediável entre a fisionomia de um mundo (os soldados que exibem a "nossa" psicologia) e a do outro (os camponeses com seu rosto opaco, sinalizador da diferença radical).

Vidas Secas trabalha o ciclo da alternância entre a chuva, forte e efêmera, e a seca, longa, geradora do inferno. O sertão é homogêneo, e a família de Fabiano traz a aflitiva dificuldade de uso da palavra, lutando na fronteira entre o "ser bicho" (como eles próprios dizem) e ser humano. Encontramos a família de Fabiano em plena 
migração, à procura de um lugar, que finalmente encontram quando vem a chuva. Feito o acordo com o dono da terra, Fabiano faz o orgulho dos meninos quando assume a identidade do vaqueiro enérgico, e mostra sua destreza na sela e no controle dos animais (que pertencem ao coronel). Mas o período de trabalho se esgota, e a seca gera nova peregrinação. A cena final do filme nos mostra a família novamente em marcha, numa experiência completamente isolada, como no início, quando a câmera a encontrou só no sertão. Quando eles se afastam, nossa memória retém este senso de dignidade do trabalho (apesar de tudo), da habilidade no confronto com a natureza e inabilidade no confronto com os homens, sinal de um futuro nada promissor na cidade, seu destino.

Deus e o diabo condensa o que vemos em Vidas Secas em um preâmbulo onde Manuel cuida do gado e Rosa trabalha a terra; mas a morte de algumas reses e a trapaça do coronel na hora da partilha geram a revolta em Manuel que, não sem antes muito pensar e hesitar, finalmente explode e mata o seu patrão. Transgressor, ele se torna um "cabra marcado para morrer", o que o leva a buscar proteção e se ligar a Sebastião, o líder messiânico. Esta adesão à experiência religiosa o leva ao isolamento em Monte Santo, quando, para evocar a história de Canudos (1897); os beatos são massacrados. O casal, sobrevivendo, é levado ao encontro de Corisco, o cangaceiro também sobrevivente de um outro massacre: o do bando de Lampião (1938). Podemos ver aqui a jornada alegórica, condensando o tempo histórico e separando bem as fases da jornada de Manuel e Rosa: O que interessa é definir uma gradual aquisição de consciência, uma gradual superação das formas equivocadas de revölta, pois a violência do cangaço também não traz justiça: é pura vingança. $O$ cangaço, em declínio, é experiência histórica condenada. $\mathrm{O}$ reconhecimento desta verdade e o discurso franco de Corisco são os méritos maiores do último cangaceiro, personagem que é visto como uma etapa preparatória à efetiva Revolução que se anuncia na repetida metáfora central do filme: o sertão vai virar mar e o mar virar sertão Tal futuro certo é concretizado pelo filme na imagem final: morto Corisco, Manuel e Rosa correm pelo sertão e a imagem do mar invade a tela, reafirmando a certeza da futura Revolução. Glauber estabelece a 
oposição entre presente (de sofrimento) e futuro (de felicidade), em termos da oposição de lugares sertão/mar. O movimento migratório típico que se repete na história - a ida para o litoral - é aqui transfigurado num movimento simbólico definitivo que vai mudar tudo. Mas a Revolução ainda está fora do alcance: Manuel não chega ao mar, nem seria esta a sua perspectiva, pois o que combinou com Rosa foi o ato de ter um filho, caso sobrevivessem ao ataque de Antônio das Mortes, o matador de cangaceiro. A fábula do filme de Glauber internaliza tudo, para isolar o sertão e fazê-lo um microcosmo capaz de simbolizar a nação, eis porque o agente repressivo é também uma figura simbólica, Antônio das Mortes, jagunço que pertence ao imaginário local; não é a polícia ou o exército que vem da cidade (elemento externo). Manuel, enquanto herói, traz a hesitação, rumina seus pensamentos, mas nele se faz valer o impulso de justiça, a revolta do oprimido, sem a qual não haveria mudança. Seu limite é sua consciência acanhada, muito presa a uma convicção visionária da salvação.

Na trilogia dos anos 60, a quebra da homogeneidade do sertão se dá em Os Fuzis. Lá estão os Manueis ou os Fabianos, mas a câmera está mais próxima dos fuzis, ou seja, dos soldados que os controlam; o drama está do lado de cá, destes homens da ordem que nos representam lá no sertão, pois o sertanejo está agora distante da câmera (não fisicamente, mas na troca dos olhares). Permanece anônimo; oferece um rosto que só reitera sua opacidade, não porque haja arrogância no olhar do cinema, mas por cautela, reconhecimento, pela recusa em representar esse Outro radical. Enigmático, o retirante leva consigo a religião, mas está aqui impulsionado pela fome, já sem forças, passivo diante dos homens da cidade.

\section{Deslocamentos: os anos 1990-2000}

Antes do salto, vale o brevíssimo resumo de um longo processo para poder dar o salto aos dias de hoje.

A trilogia do Cinema Novo se fez no momento em que o golpe de 1964 instalou a ditadura militar, momento a partir do qual houve nítidas mudanças no tratamento da experiência do oprimido, 
ou mesmo do Brasil como um todo. Glauber Rocha, em particular, viveu o seu momento de desencanto barroco expresso no teatro de Terra em Transe (1967) e, em 1969, fez $O$ dragão da maldade contra o santo guerreiro, cuja representação do sertão já reconhecia a sua contaminação pelo moderno, a sua nova condição de lugar de passagem, com estradas, flores de plástico e caminhões. Para isto, porém, localizou a sua fábula na própria década de 1960, tomando a presença do cangaceiro como ensaio e repetição, sobrevivência de uma reserva moral de rebeldia já condenada pelos deslocamentos do país e pela temporalidade do avanço técnico a se impor diante da cultura e das formas de poder locais. Nos anos 1970, a tônica dos filmes passa a ser de amarga melancolia ou sarcasmo no reconhecimento da derrota do projeto político da década anterior. Há a emergência do indígena e da Amazônia como pólo de reflexão e de alegoria política, pois o nativo era a figura do massacrado por excelência. Macunaíma (1969), Como era gostoso meu francês (1971) e Iracema (1974) são exemplos dessa representação a partir da ótica dos vencidos. E essa tônica anti-épica no trato da experiência prevaleceu até os anos 1980, quando o cinema acentuou problemas e fracasso ao focalizar uma variedade de imigrantes atrelados a sonhos de riqueza na nova terra, viessem de onde viessem: Paraguai, Japão, interior do Brasil (Amazônia, nordeste, centro-oeste).

O que chamamos de "cinema da retomada" abordou esses temas com nova sensibilidade, introduzindo nuances, voltando-se mais para experiência individual, dando mais atenção a situações atípicas. Passamos da migração como "necessidade social" para a migração como contingência, experiência singular, individual. Há nesse cinema dos anos 1990-2000, a presença maior do estrangeiro, personagens em trânsito, o que dá ensejo a encontros que atravessam culturas, tal como é frequiente no cinema contemporâneo, um traço transnacional que o cinema brasileiro vem partilhar, numa alteração de sensibilidade que se projeta até mesmo nos filmes que focalizam experiências do passado. Os grandes deslocamentos espaciais, as interações que envolvem o local e o estrangeiro, tiveram seu efeito na estrutura dramática do cinema recente, em vários países. Ganhou força no cinema a representação do que chamei de "encontro inesperado", 
presente em muitos filmes recentes, não só brasileiros (Xavier, 2003). Houve mudanças na composição de personagens e nos enredos, mudanças que criaram uma nova configuração para a questão da identidade, mais fluida, de contornos menos rígidos, e o motivo do encontro inesperado se torna uma nova figuração da contingência. Esta se afirma pela irrupção de um momento especial que reúne dois indivíduos que se interceptam sem antes ter nada em comum. Claro que encontros inesperados não são novos na ficção, mas no novo contexto eles criam um paradigma que, observado de filme a filme, expressa a busca de uma nova percepção no trato de temas clássicos do cinema - da violência urbana às migrações. A força da contingência, como traço marcante da experiência a tematizar, tem no campo das migrações um terreno fértil de manifestação e interesse dramático, tal como vemos nos filmes que focalizam o sertão, não apenas o que se inscreve no Brasil de hoje, mas também aquele sertão de $1930-40$ que vimos na trilogia do Cinema Novo. Agora, o que interessa é o evento singular que se produz quando dois indivíduos, representando figuras de radical alteridade um para o outro, se encontram em uma situação explorada com talento em Baile perfumado (1996), de Paulo Caldas e Lírio Ferreira, e em Cinema, aspirinas e urubus (2005), de Marcelo Gomes.

\section{Baile perfumado}

Devo, primeiro, esclarecer que os imigrantes estrangeiros tiveram um enorme papel na prática cinematográfica do início do século no Brasil. Os estudos históricos nos trazem esta presença dos então excluídos da cultura legítima como grandes impulsionadores da atividade. Tal fato teve lugar nas cidades grandes. Em São Paulo, por exemplo, os imigrantes italianos pobres, em alguns casos em associações culturais de operários, fizeram cinema - quase sempre documentário (Galvão, 1975). E era comum no Brasil a experiência de um imigrante vindo da Europa ou do Oriente Médio, familiarizado com a técnica e com o comércio, viajar para fazer registros de famílias e fazendas, enfim de gente rica, como um ganha pão. A crítica de cinema não os apreciava; eram chamados "cavadores", vistos como 
"sem compromisso" com a Arte do Cinema. E são raras as homenagens a tais figuras nos filmes brasileiros.

Baile perfumado sinaliza; então, duas alterações na sensibilidade dos cineastas. De um lado, destaca a história do cinegrafista que filmou Lampião nos anos 30 e acentua, pela primeira vez, o fato de que Benjamin Abrahão era um imigrante libanês, de forma a pautar a relação entre o cineasta e o cangaceiro como algo pertencente ao arco de "encontros transnacionais". De outro, há um tratamento de Lampião que reflete a cultura jovem dos anos 90 , ativadora de uma iconografia que mescla o antigo e o pós-moderno, inscrevendo o cangaceiro num contexto de citações dentro do qual ele recebe homenagem póstuma como um ícone a que podemos nos ligar pelo carisma da figura, mais do que por uma discussão aprofundada do sentido social de sua prática. Com tais parâmetros, a representação do espaço do cangaço como "zona de fronteira" muda também de natureża, pois, ao contrário do que acontecia em Deus e o diabo na terra do sol, a ênfase agora é dada à rede de contaminações do rural pelo urbano, num circuito onde se insere o cangaceiro endinheirado como consumidor de bens importados. Altera-se o estatuto do sertão. Antes este era um microcosmo fechado, espaço mítico onde se profetizavam revoluções; agora é um território inserido no sistema de trocas comerciais - que abriga um modo de vida "aburguesado" em plena caatinga.

A figura do bandido social dissolve suas conotações românticas e mergulha no espaço em que tudo é circulação de mercadorias, mundo da troca que conecta o sertão e o mar. Perfumes, garrafas de whisky, tudo tem seu lugar no sertão, e Lampião e Maria Bonita vão à cidade e ao cinema. Por seu lado, Benjamin Abrahão filma os cangaceiros no sertão. O eixo de Baile perfumado é este encontro singular no qual o homem com a câmera se faz protagonista maior da história que nos revela a forma como capturou as imagens que serviram de inspiração para Paulo Caldas e Lírio Ferreira, e para o título que evoca ironicamente a vaidade do cangaceiro. No filme de Glauber, havia o orgulho e a vaidade, mas não o consumo, e havia o sacrifício e a busca de justiça típica à figura do bandido social. Com o declínio deste tipo, o Lampião de Baile perfumado é apenas 
ambicioso, e chega a compor uma fisionomia de farsa. A música e o estilo da montagem o celebram como um item peculiar numa galeria de máscaras que deslocam a política para compor outra ordem de construção mítica. Do romantismo passamos ao pop.

Baile perfumado compõe uma nova auto-imagem do cineasta. $\mathrm{O}$ encontro singular de Benjamin Abrahão com Lampião acentua a habilidade e esperteza do cineasta na viabilização do que se julgava impossível: filmar o cangaceiro em seu próprio terreno. A identificação de Paulo Caldas e Lírio Ferreira com o cineasta dos anos 30 não supõe um mandato político, nem qualquer utopia. Há o relato de uma contingência histórica feita da conexão entre o filme de Abrahão e a modernização que acabou resultando na morte de Lampião, figura incompatível com os projetos do Estado Novo, poder centralizador que não podia aceitar a imagem dos cangaceiros nas telas, um sinal do que considerava um arcaísmo a exterminar. $\mathbf{O}$ legado de Benjamin Abrahão, embora satisfaça um anseio de posteridade na ótica de Lampião, é um documento precioso que se fez também signo de morte, para os cangaceiros e para o cineasta.

A morte é então o destino partilhado, mas não há a preocupação de compor uma moldura ideológica a unificar o bandido e o cineasta. Ambos se destituem de seu apelo revolucionário, e Benjamin se exibe como o homem inquieto que buscou Lampião a partir de um senso de oportunidade, de ousadia. Teve tino comercial, talento na negociação com os poderosos, intuição da importância da imagem na cultura e sua rentabilidade. $O$ filme dele se aproxima com olhar simpático diante de suas negociações e de seu carisma que seduziu até Lampião. Há uma narração em voz over que expõe o seu pensamento que se expressa em língua árabe, de forma a ressaltar sua cultura de origem. Ele faz um diário, anota, escreve; ao contrário das pessoas com quem interage. Há em sua voz over a presença de uma subjetividade-alteridade que adensa a sua figura, pois o seu sotaque "em cena" e as suas manobras poderiam gerar um estereótipo. Desse efeito, Benjamin escapa, pois o seu ponto forte é a urbanidade, a condição de homem do mundo cujas andanças o tornaram, a uma certa altura, o secretário de Padre Cícero em Juazeiro. 
O que vale para os cineastas dos anos 90 é o pragmatismo, não a revolução, este traço simbólico comum que unia o bandido social ao cineasta com ele identificado, como Glauber Rocha com Corisco.

\section{Cinema, aspirinas e urubus}

Cinema, aspirinas e urubus focaliza um jovem alemão que conduz seu caminhão pelo sertão. Leva consigo equipamento de cinema - projetor e tela - mostrando pelos vilarejos um filme de propaganda sobre o progresso de São Paulo e sobre as virtudes da aspirina. É um funcionário da Bayer a trazer a novidade para este quase deserto, vendendo o remédio como se fosse milagroso, depois da magia do cinema preparar o clima. $\mathrm{O}$ encontro inesperado lembra aqui o filme de Wim Wenders, No decorrer do tempo (1976): um profissional conectado ao cinema dá carona à um desconhecido. Esta é ocasião para um reconhecimento mútuo, uma travessia de distâncias culturais e sociais, sondagem de interesses comuns. No caso, tais interesses ficam logo evidentes: Johan, o alemão, se beneficia da presença de Ranulfo, o sertanejo, que joga como mediador cultural è o auxilia, mas reivindica um salário e aulas para manusear o projetor e dirigir o caminhão. A viagem se torna, para Ranulfo, uma escola da qual ele não hesita em tirar proveito. $O$ ponto final da travessia é um vilarejo de nome irônico - Triunfo, um lugar onde eles são recebidos pelo prefeito que exalta o progresso e quer comerciar, interessadíssimo na aspirina. Ele quer ser moderno e recusa ser chamado de "coronel": sou empresário, ele corrige.

Os dados da modernidade chegam ao sertão. Na imagem de abertura, $o$ excesso de luz que invade a tela não abate, neste caso, $o$ ânimo dos retirantes, como em Vidas Secas e $O$ s fuzis; a luz dèstaca um espelho retrovisor, um caminhão, uma estrada, um motorista. Instala-se de imediato um road-movie em plena terra do Sol e da seca. A pobreza continua visível, mas agora mantida a uma certa distância, o que não a impede,' às vezes, de passar junto da câmera com figuras tão enigmáticas quanto os anônimos que encaramos em $O s$ fuzis. 
Em sua singularidade, o sertanejo que interage com o visitante parece uma figura já curtida por outras viagens, sabe ler e tẹ fala solta, é hábil no uso dos provérbios, e não pára de se queixar de sụa terra - "lugar infame", como ele diz. Fica surpreso com as reações do alemão que vê interesse em tudo; por seu lado, Johan denuncia a má vontade de Ranulfo com seus conterrâneos, como se ele não fizesse parte do sertão. Quando perguntado por tal pertinência, responde com um gesto que sugere, "sim e não". Pondo-se à parte, ele olha o sertão como um "fim de mundo" a que nada chega, nem as guerras (veremos que está errado). Reitera, a seu modo, o clichê da excepcionalidade brasileira. As suas frases, sobre o sertão como um mundo à parte, trazem a ambigüidade já conhecida pelos brasileiros: a exclusão é aí vivida, ao mesmo tempo, como condenação e privilégio. $\mathrm{Na}$ dúvida, a sụa postura é a da esperteza de quem sabe aproveitar a oportunidade. Não é um Fabiano, ingênuo e bronco; tem consciência de outros mundos, fala do Rio de Janeiro, embora com ressentimento, a partir de relatos de viagem que depois dirá serem mentira. Enfim, faz seus jogos e, apesar da rabugice, conquista a amizade de Johan. Seu movimento inclui o interesse, mas seu afeto o faz leal ao amigo, até o fim. A despedida será solidária.

A viagem de Ranulfo não é uma peregrinação à procura da justiça; é a ocasião do cultivo da amizade. Ele não entra no caminhão para representar uma coletividade, embora expresse em seus modos e em sua fala a inserção numa cultura a partir de alguns cacoetes, como a má vontade com o Brasil e o auto-elogio. Com sorte e pragmatismo, ele vê o seu destino se alterar de forma abrupta.

Estamos em 1942, e as notícias da Guerra Mundial chegam ao caminhão pelo rádio de Johan, pontuando a jornada. Perto do final do filme, vem o anúncio de que o Brasil declarou guerra à Alemanha; na sequiência seguinte, Johan recebe pelo correio um documento que explica a intervenção oficial na Companhia Bayer, e a ordem para que ele vá para um campo de concentração em território brasileiro, ou vá embora, aceitando o destino de soldado alemão, condição de que ele fugiu e de que se julgava livre nos confins do sertão, onde afinal a Guerra chega. Resta jogar fora de vez a sua identidade alemã (o passaporte) e ir para um lugar mais distante. Ele parte para a 
Amazônia, junto com uma massa de retirantes nordestinos, os ditos "soldados da borracha", a mão de obra de um projeto do governo brasileiro inserido no esforço de guerra: produzir borracha para os USA. A deriva de Johan o torna um retirante sem nome que partilha o destino de brasileiros pobres ironicamente enredados na Guerra. Seu gesto de desterritorialização implica em escolher uma das alternativas postas pela malha dos poderes nacionais que sempre rejeitou em nome de uma disposição humanista ao diálogo sem fronteiras.

A uma certa altura, ele diz a Ranulfo "não quero matar gente". No final, quando a declaração de guerra os torna "em princípio" inimigos, eles brincam e, numa cena notável, matam-se simbolicamente aos risos, para celebrar a amizade. Na despedida, Ranulfo ganhă um presente: a chave do caminhão. Feliz, assume a direção, mas não fica claro para onde vai, pois é pouco provável que assuma o emprego do seu amigo nas novas circunstâncias. De qualquer modo, adquiriu novos saberes que o distanciam do sertanejo comum; está livre no curto prazo. Não é o Fabiano - pobre caminhante que vai ser explorado na cidade. E não é o Manuel de Glauber Rocha, cuja corrida despojada pelo sertão imenso é alegórica, tanto quanto o mar que invade a tela no final. Na direção do veículo, Ranulfo é o sertanejo que sorri como um menino porque a Guerra lhe deu um encontro inesperado e um presente de que pode usufruir sem culpa. $\mathrm{Se}$, no futuro imediato, estiver fora do lugar, pelo menos não terá sobre si o peso da crise de identidade e do senso de exílio dos conterrâneos de Johan que, nos anos 70, vimos nos filmes de Wim Wenders a se deslocar num país estranhado com seu próprio passado. Observar Ranulfo neste final é evocar um momento de inocência, um simpático lampejo de felicidade trazido por uma contingência que ele incorpora como um lance individual de curto prazo que nos encanta.

Ao volante, o sertanejo avança "leve e solto", pois seu movimento não supõe desdobramentos históricos de grande monta. É a fruição da contingência, a captura do momento, em contraste com a penosa corrida de Manuel que, alegoria da esperança, carregava, no entanto, em sua performance o que hoje é comum se observar, com alívio ou angústia, como o fardo da utopia. 


\section{Bibliografia}

BENTES, I. 2003. The sertão and the favela in contemporary Brazilian film. In: NAGIB, L. (org.). The New Brazilian Cinema. Londres: I.B.Tauris.

BOAVENTURA, M. C. 2002. Redescobrindo o sertão. In: GUIMARÃES, C.; VAZ, P. B.; SILVA, R. H.; FRANÇA, V. Imagens do Brasil: modos de ver, modos de conviver. Belo Horizonte: Autêntica.

GALVÃ̃, M. R. 1975. Crônica do cinema paulistano. São Paulo: Ática. HOBSBAWN, E. 1975. Bandidos. Rio de Janeiro: ForenseUniversitária.

XAVIER, I. 2000. "O cinema brasileiro dos anos 90". Praga - estudos marxistas, São Paulo, vol. 9, p. 97-138.

2003. Brazilian cinema in the 1990s: the unexpected encounter and the resentful character. In: NAGIB, L. (org.), The New Brazilian Cinema. London: I.B.Tauris.

\section{Filmografia}

BAILE PERFUMADO. 1996. Diretor: Paulo Caldas e Lírio Ferreira CINEMA, ASPIRINAS E URUBUS. 2005. Diretor: Marcelo Gomes COMO ERA GOSTOSO MEU FRANCÊS. 1971. Diretor: Nelson Pereira dos Santos

DEUSEODIABONA TERRA DO SOL. 1963. Diretor: Glauber Rocha. IRACEMA. 1974. Diretor: Jorge Bodansky e Orlando Senna. MACUNAÍMA. 1969. Diretor: Joaquim Pedro de Andrade NO DECORRER DO TEMPO. 1976. Diretor: Wim Wenders

O CANGACEIRO. 1953. Diretor: Lima Barreto.

O DRAGÃO DA MALDADE CONTRA O SANTO GUERREIRO. 1969. Diretor: Glauber Rocha.

OS FUZIS. 1963, Diretor: Ruy Guerra

TERRA EM TRANSE. 1967. Diretor: Glauber Rocha.

VIDAS SECAS. 1963. Diretor: Nelson Pereira dos Santos. 